\title{
Diálogo e interações face a face: a força da oralidade na comunicação interna
}

Dialogue and face to face interactions:

the power of oral speech in internal communication

El diálogo y la interacción cara a cara:

la fuerza de la oralidad en la comunicación interna

Marta Terezinha Motta Campos Martins

- Doutora e mestre em Ciências da Comunicação pela Escola de Comunicações e Artes da Universidade de São Paulo (ECA-USP)

- Professora adjunta do Curso de Relações Públicas, do Departamento de Comunicação da Universidade Estadual de Londrina (UEL)

- Tem experiência na área de comunicação, com ênfase em relações públicas, atuando principalmente nos seguintes temas: relações públicas, comunicação, comunicação estratégica, marketing e comunicação interna

- E-mail:mmartins@uel.br 


\section{ANO 10 • NÚMERO $19 \cdot 2^{\circ}$ sem 2013 • ORGANICOM \\ DIÁLOGO E INTERAÇÕES FACE A FACE: \\ A FORÇA DA ORALIDADE NA COMUNICAÇÃO INTERNA}

Resumo

O interesse da pesquisa aqui apresentada, recorte da tese de doutorado defendida pela autora na Escola de Comunicações e Artes da Universidade de São Paulo (ECA-USP), sob orientação da Profa. Dra. Margarida Kunsch, situou-se no campo das manifestações e dos usos da fala. 0 corpus foi constituído em torno da oralidade observada nas interações entre líderes e empregados de uma empresa estatal situada na região norte do Paraná. A análise exigiu um enfoque quali-quantitativo, destacando-se aqui o quantitativo. As conclusões permitem afirmar que o uso da oralidade na prática de comunicação interna é fortemente reconhecido por sua capacidade de promover interações de elevado impacto na produtividade e na performance da equipe em seu conjunto.

PALAVRAS CHAVE: INTERAÇÃO • FACE A FACE • ORALIDADE • COMUNICAÇÃO INTERNA.

\section{Abstract}

The aim of this research, as part of a doctoral thesis defended by the author at the University of Sao Paulo's School of Communication and Arts (ECA-USP), under the guidance of Prof. Dr. Margarida Kunsch, is to focus on the use of manifestations and uses of oral speech. The data gathered comprises oral communication practices as observed in the interactions between leaders and employees at a state-owned company located in the northern region of the state of Parana, Brazil. The research required both a qualitative and a quantitative approach, and here we concentrate on the latter. The findings firmly suggest that the use of oral speech in internal communication is strongly acknowledged for its ability to foster high-impact interactions on the team overall productivity and performance.

KEYWORDS: INTERACTION • FACE TO FACE • ORALITY • INTERNAL COMMUNICATION.

\section{Resumen}

El interés de la investigación aquí presentada, es un recorte de la tesis de doctorado defendida por la autora en la Escuela de Comunicaciones y Artes de la Universidad de São Paulo (ECA-USP), bajo la orientación de la Profa. Dra. Margarida Kunsch, se situó en el campo de las manifestaciones y de los usos del habla. La investigación tuvo la comunicación interna como objeto y el contorno de la pesquisa fue el uso de la oralidad entre líderes y empleados en una empresa estatal situada en el norte de Paraná. La oralidad es un capítulo complejo de las ciencias sociales y la investigación pidió una aproximación cuantitativa y cualitativa. Una medida cuantitativa llenó el propósito de enfrentar el pensamiento del líder, sobre el uso oralidad en la práctica de la comunicación interna, con la percepción de los seguidores sobre lo que realmente ocurre en una organización pública. 


\section{ANO 10 • NÚMERO $19 \cdot 2^{2}$ sem $2013 \cdot$ ORGANICOM DIÁLOGO E INTERAÇÕES FACE A FACE: A FORÇA DA ORALIDADE NA COMUNICAÇÃO INTERNA}

C omunicar bem não é, isoladamente, ser capaz de transmitir ou receber bem as informações de diversas fontes e tipos. Comunicação implica troca e entendimento, e não é possível entender e se fazer entender sem considerar, além das palavras, as emoções e a situação em que ocorre o compartilhamento de conhecimentos, ideias, instruções ou qualquer outra mensagem, seja ela oral, escrita ou corporal. Daí sua complexidade e razão permanente para buscar analisar a comunicação em diferentes dimensões - e aqui se situa o campo da oralidade. Muitas vezes confundido com pura informalidade, nele nem sempre se reconhece o potencial de transportar intensamente todos esses aspectos mencionados.

0 público é capaz de perceber, pelo discurso falado, o comportamento e as opiniões que constituem os reais valores de um interlocutor e de seu papel naquela ocasião. "Um papel sustenta o outro. Esses 'papéis', que na realidade se baseiam em pressupostos e opiniões, também interferem no diálogo" (Bohm, 2005, p. 70). Os níveis intrapessoal e interpessoal de comunicação necessitam ser flexíveis e facilitar tanto o processamento quanto a percepção sobre a informação. Numa cultura de acentuada informalidade como a brasileira, o uso da comunicação oral está ainda diretamente associado à natureza das interlocuções e das interações entre atores sociais. Cabe, portanto, problematizar e observar a oralidade e os atos comunicacionais originados por meio da fala, para que sua função como componente natural de comunicação não seja relegada a um plano secundário. Esse é um tipo de conhecimento que fará falta no moderno ambiente organizacional.

O universo selecionado para desenvolver o estudo empírico aqui relatado foi uma empresa estatal, tendo a investigação sido concentrada na proposta de conhecer o alcance da oralidade na comunicação organizacional interna da empresa. Conforme Margarida Kunsch (2003), políticas, estratégias e programas de ação são construídos dentro de um plano de comunicação interna que vise à interação efetiva entre a organização e seus empregados. Diz a autora:

A importância da comunicação interna reside sobretudo nas possibilidades que oferece de estimular o diálogo e a troca de informações entre a gestão executiva e a base operacional, na busca da qualidade total dos produtos ou serviços e do cumprimento da missão de qualquer organização (Kunsch, 2003, p. 159).

Um plano estratégico de comunicação interna contempla uma abordagem sobre a importância do líder como interlocutor de informações e sobre a questão da retórica utilizada pelas lideranças organizacionais. A argumentação eliciada por um líder centra-se na oralidade e por ela pode-se explicar a comunicação. 0 contexto apresentado corrobora a consideração de elementos de ordem afetiva e de ordem racional que sustentam o campo do pensamento científico denominado retórica. 0 caráter estratégico de um discurso organizacional está condicionado ao equilíbrio entre o discurso e as ações praticadas, embora estudiosos como Tereza L. Halliday (2009) defendam que essa dicotomia não se aplica, posto que discurso é ação. 0 aspecto que se vem formulando até este ponto fundamenta-se nesse mesmo princípio, visto que a proposta é estudar as dimensões da oralidade que the permitam alcançar a aspiração da comunicação interna estrategicamente nela focada.

O objetivo geral colocado para a pesquisa de doutorado foi investigar de que modo a oralidade produzia impactos para resgatar e fortalecer o diálogo entre líderes e empregados e para projetá-la ao campo das estratégias de comunicação interna. A pesquisa ocorreu em três etapas, delimitadas a partir dos requisitos contidos na caracterização de cada método científico utilizado. A multiplicidade de métodos foi imprescindível para alcançar os objetivos propostos e a problematização da pesquisa esquematizou uma primeira fase ancorada pela fenomenologia, a preservação da abordagem qualitativa na segunda etapa e uma terceira fase de caráter quantitativo. 0 que aqui se apresenta como resultado é o que foi possível concluir da etapa quantitativa na pesquisa. 


\section{ANO 10 • NÚMERO $19 \cdot 2^{2}$ sem $2013 \cdot$ ORGANICOM DIÁLOGO E INTERAÇÕES FACE A FACE: A FORÇA DA ORALIDADE NA COMUNICAÇÃO INTERNA}

\section{POR QUE COMUNICAÇÃO FACE A FACE}

Nas organizações, ambiente do recorte espacial desta investigação, um pressuposto adotado, logo de início, foi que a fala é o componente que promove interação e possibilita exprimir o pensamento de modo diverso em relação ao da linguagem escrita. Compreendida dessa maneira, a oralidade se faz presente nas demandas dos grupos que integram a organização, na prática do diálogo, na comunicação face a face, na comunicação interpessoal, em todos eles como um meio de conduzir um processo sempre mediado pela palavra falada.

Etimologicamente, oralidade remete àquilo que não é efetuado por escrito. Como procedimento comunicacional, a oralidade consente que interlocutores utilizem exclusivamente a fala para interagir e para se expressar. Os novos tempos tornam evidente que a comunicação interna necessita estimular o diálogo, as interlocuções diretas e a comunicação face a face entre gerentes e funcionários para alcançar bons resultados de produção, de identidade e de negócios para as organizações. Basicamente, hoje, a oralidade circula pelos aparatos das novas tecnologias por meio das quais as pessoas se comunicam no seu dia a dia.

Um programa de comunicação interna parte do estabelecimento de metas que são vislumbradas pela análise estratégica da organização, conforme defende Paul Argenti (2006, p. 169) e implicando "mais do que memorandos, publicações e as respectivas transmissões. Envolve desenvolver uma cultura corporativa e ter o potencial de motivar a mudança organizacional". Evidentemente, hoje a tecnologia dá suporte para que as organizações alcancem a expansão necessária para se inserir em mercados globais e, para que isso possa ser conseguido, almeja-se que o processo de comunicação seja analisado em sua totalidade.

0 papel da comunicação interna é contribuir com a construção do conhecimento entre as equipes de funcionários a fim de que a organização projete, para a sociedade, um comportamento coerente e no mesmo compasso com o que desejam seus públicos estratégicos. Trata-se de um processo de modernização que preveja tecnologia avançada como suporte para o capital humano sintonizar a linguagem da máquina com a linguagem corrente entre os atores da modernidade. 0 caráter estratégico da comunicação interna associa a missão organizacional às operações convencionais de uma sociedade cujos limites geográficos são inimagináveis. Essa particularidade terá alcance a partir do equilíbrio entre a comunicação humana e a comunicação tecnológica, inseridas internamente na rotina cotidiana de organizações atualizadas.

Percebe-se a necessidade de abdicar de formas individualistas de se pensar o mundo, a sociedade e a missão organizacional como instâncias contíguas, pois as interações estão assentadas na tecnologia como mediadora de relações que são humanas. Diante disso, a cultura vigente valoriza organizações que constroem um ambiente comunicacional "desobstruído" e que estabeleçam uma política de comunicação radicada por relações dialógicas, as quais ganham visibilidade mediante uma oralidade aceita e adequada à sua cultura. Concebe-se a reinserção da oralidade no campo de estudos da ciência da comunicação como uma forma de mediação necessária para que os sujeitos organizacionais desenvolvam interações que os tornem protagonistas no alcance dos objetivos traçados no plano global e estratégico das empresas.

Gail Fairhurst e Linda Putnam (2010, p. 109) analisam a comunicação como um construto "que inclui pesquisa fora dos estudos do discurso, como por exemplo análise de redes de relacionamento, processamento de informação e de fluxo de mensagens". A comunicação interna como espaço para contatos interpessoais compreende a inclusão de funcionários, como também dos gestores e dirigentes localizados nos níveis hierárquicos mais elevados da organização. Nos dias atuais, 


\section{ANO 10 • NÚMERO $19 \cdot 2^{2}$ sem $2013 \cdot$ ORGANICOM DIÁLOGO E INTERAÇÕES FACE A FACE: A FORÇA DA ORALIDADE NA COMUNICAÇÃO INTERNA}

a comunicação compete com outros interesses e com outras informações, de modo que o desafio lançado é equilibrar os interesses e dosar a comunicação face a face perante o outro universo comunicacional que é calcado na tecnologia. Comunica hoje 0 ator social que convida seu interlocutor a uma nova forma de conversa, na qual dialogar significa também escutar.

A palavra é a forma primária da linguagem empregada em uma dinâmica natural de compartilhamento entre atores sociais quando mobilizados para se comunicar. Afirma Mikhail Bakhtin (1986) que a palavra é uma função do interlocutor. 0 meio social, do qual o interlocutor faz parte, influencia suas interpretações, sua expressão e sua visão de mundo. A análise de Bakhtin considera que qualquer palavra "comporta duas faces. Ela é determinada tanto pelo fato de que procede de alguém, como pelo fato de que se dirige para alguém. Ela constitui justamente o produto da interação do locutor e do ouvinte" (Bakhtin, 1986, p. 113 - grifo do autor). 0 diálogo é uma estratégia para se percorrer uma trajetória fértil, tanto para os negócios, como para os relacionamentos públicos. Olhar para dentro e ouvir a si mesmo completa a análise de cenários, 0 encontro e a proposição de soluções comunicacionais para as empresas. 0 contato direto é dos mais relevantes pontos a serem absorvidos para que a comunicação ocorra de modo eficaz, particularmente por meio do contato face a face.

Afirma Thomaz Larkin (2005) que o uso de veículo impresso ou eletrônico pode ocorrer na comunicação interna, mas que empregados querem uma relação direta com seus gestores, fazer perguntas, ouvir respostas. Atualmente há uma redução significativa na lealdade, pois um interlocutor insatisfeito pode jogar seu problema em um blog, porque a empresa não enxergou que comprometimento é a palavra de ordem para sua performance. Recomenda Larkin (2005, p. 6) que, "quando os funcionários entendem o que você quer dizer, mas eles não querem, não aceitam ou são contra, aí tem que ser comunicação face a face". Esta é uma teoria reafirmada por Bohm (2005, p. 58) ao defender que "todas as discussões sérias, seja na família ou nos grupos de diálogo, se dão sobre pontos de vista diferentes a respeito do que é absolutamente necessário".

Instiga-se a pensar a comunicação face a face nos casos em que os funcionários tenham reservas pessoais com seus superiores, os quais serão os praticantes de interlocuções com a equipe. Resultados de pesquisas mostram que os empregados estão sensíveis aos superiores que utilizam a comunicação face a face nos ambientes organizacionais. Larkin (2005) informou que 70\% dos empregados admitiam o face-a-face como um modelo ideal de comunicação de resultados internos. A importância da comunicação está nas relações interpessoais e envolve o universo que permite criar relacionamento. Desenvolver habilidade para comunicação significa transmitir ideias, conceitos e competências, visando comunicar métodos e técnicas de trabalho para atingir objetivos pré-estabelecidos. Possivelmente, o emprego de métodos e técnicas inadequados provoquem confusão quanto ao sentido de certas expressões e pensamentos expostos na comunicação face a face. Outros fatores de estrangulamento a esse tipo de comunicação são o despreparo para receber determinada comunicação, as mensagens longas e sem conteúdo. Nem toda informação exige o face-a-face, e este é um tipo de comunicação indispensável nas situações em que ocorre resistência do público interno e para desvendar 0 que 0 empregado quer. 0 líder com habilidade para o face-a-face é igualmente hábil para exposições orais.

\section{INTERAÇÕES FACE A FACE E ORALIDADE}

A oralidade é uma forma de contato entre indivíduos em que a comunicação verbal se relaciona diretamente com a nãoverbal. Gera significados promulgados em gestos, expressões e atitudes que são compreendidos e interpretados pelas pessoas. Três elementos compõem a oralidade: a voz, a fala e as manifestações do corpo que marcam presença no processo de comunicação. A voz e a fala são carregadas de significados que ajudam ou atrapalham as interações dos atores daquela situação comunicacional. Conhecer os elementos da comunicação oral que influenciam a transmissão das informações organizacionais e, principalmente, saber controlá-los durante o processo de interação com funcionários é fundamental para executivos e empregados de organizações que prezam por uma comunicação de resultados. 


\section{ANO 10 • NÚMERO $19 \cdot 2^{2}$ sem $2013 \cdot$ ORGANICOM DIÁLOGO E INTERACCÕES FACE A FACE: A FORÇA DA ORALIDADE NA COMUNICAÇÃO INTERNA}

Voz, fala e manifestações do corpo compõem a expressividade das pessoas. O maior ou menor domínio dessa expressividade é o que determina se o objetivo da comunicação será ou não alcançado. Tão importante quanto saber o que dizer nos momentos de manifestação oral, é saber a forma mais adequada de dizê-lo e estar preparado para isso. A comunicação oral será estratégica quando executivos e funcionários souberem estabelecer interação, comunicar-se de forma clara e precisa, ser entendidos e receber o feedback para estender o diálogo entre os atores internos da organização.

A inspiração para defender o emprego da oralidade como estratégia de comunicação interna vem de Erving Goffman (2011) analisando o "ritual de interação". Na concepção do autor, a interação face a face envolve um breve período de tempo, um limite espacial, e seus eventos têm início, meio e fim quando inseridos nesses limites. Pessoas compartilhando um mesmo espaço físico e temporal estabelecem uma presença que imediatamente gera comportamentos distintos, em termos tanto de padrões quanto de atividade interacional. Afirma Goffman que a fachada, sentido original do inglês face, é um valor social que pode ser traduzido pelo grupo como o respeito ao outro. A fachada é, então, o modo como a pessoa aspira a ser acolhida pelos demais participantes da interação. Particularmente nos contatos pessoais diretos, a fachada tende a se revelar com total clareza e resplandescência.

A pessoa cuja fachada atingiu valor social positivo experimentará o sentimento de confiança. Não basta o respeito próprio, pois o respeito ao outro é condição para que este desempenhe seu papel, conforme sua própria escolha para aquela ocasião. A aceitação mútua é a estrutura elementar para interação e conversa face a face, pois, por mais triviais que sejam ou pareçam ser as ocasiões de fala, o uso da oralidade exige que cada participante manifeste uma preocupação genuína consigo e com o outro. Fica perceptível que são imputadas convenções para que as conversas sejam tomadas como uma solução eficaz e suficiente para organizar fluxos de mensagens projetadas por meio da comunicação oral.

Uma pessoa transita por distintos grupos e adota proporcionalmente códigos de conduta apropriados a cada situação vivenciada, contudo o protocolo dos diálogos é reaplicável, ainda que ajustados aos objetivos de cada grupo. 0 líder é a pessoa que vincula sua posição em sintonia com a posição dos liderados para que esta seja uma relação social possível no ambiente corporativo. 0 relacionamento social força pessoas a confiarem sua imagem aos atos dos outros participantes legítimos de um grupo. Ao proceder a uma análise relacional das ocasiões de fala, preconiza-se que este movimento que é acionado por meio do diálogo e das interações face a face, retroalimenta a função e o reconhecimento formal da liderança.

Goffman afirma que o indivíduo absorve regras de conduta que representam um guia para a ação. Fala-se assim do cumprimento de ações que podem parecer um dever agradável, desejável ou desagradável. Nos relacionamentos internos, a equipe de empregados convive com sinais não verbais representativos da hierarquia formal da empresa. A imagem de um líder é uma construção particular da equipe ou do grupo de liderados que sofre impacto muito forte da comunicação oral inserida no repertório da comunicação interna. Os atos cerimoniais realizados por uma pessoa numa interação falada com outras pessoas conduz à formação de sua imagem, aos olhos de cada participante do grupo, naquele evento de uso da oralidade. A comunicação face a face permite que a conversação seja espontânea, apesar de fazer exigências em nome da manutenção do diálogo. Na presença imediata entre pessoas, um repertório de palavras, de gestos, regras de conduta, atos e outros eventos - conversas paralelas, por exemplo - apresentam-se e são componentes edificáveis da imagem que 0 ator da comunicação falada projeta para os receptores. Como processo, a comunicação implica compartilhamento, negociação e deslocamento de posição entre falante e ouvinte. 


\section{ANO 10 • NÚMERO $19 \cdot 2^{2}$ sem $2013 \cdot$ ORGANICOM DIÁLOGO E INTERAÇÕES FACE A FACE: A FORÇA DA ORALIDADE NA COMUNICAÇÃO INTERNA}

\section{MÉTODOS UTILIZADOS}

Nossa pesquisa foi estruturada a partir de uma sucessão de recortes compreendendo: assunto comunicação interna recortado pelo tema uso da oralidade, por sua vez recortado pelo problema de verificar que visão os envolvidos tinham do universo de interação que estavam criando e de que modo compreendiam as consequências que isso produzia para seu desempenho e sua produtividade. Oralidade é um tema complexo das ciências sociais e essa complexidade incide, igualmente, sobre seu recorte. Portanto, a pesquisa empírica, realizada na comunicação entre líderes e equipes de empregados de uma organização, exigiu o cumprimento de três etapas: a primeira com os dirigentes da estatal; na segunda adotou-se o nível de supervisão e gerência como sujeitos; e na terceira, que foi quantitativa, tomaram-se como sujeitos todos os empregados da empresa. A etapa quantitativa - e aqui se fundamenta o relato deste artigo - preencheu a finalidade de confrontar 0 pensamento das lideranças sobre o uso da oralidade na prática de comunicação interna, com a percepção dos liderados sobre o que de fato ocorria no universo investigado. As entrevistas com os funcionários tiveram como instrumento de coleta questionários semiestruturados.

A definição da empresa a ser pesquisada deu-se pelo seu porte, pela atuação internacional, como também pelo seu ramo de atividades envolvendo pesquisa e produção de tecnologias que contribuem com o desenvolvimento econômico, social e científico da sociedade brasileira. Era, portanto, uma pesquisa em instituição que também faz pesquisa. A abordagem quantitativa foi realizada com todos os empregados que sofressem impacto da comunicação interna da empresa, estivessem acessíveis à época da coleta de dados e não tivessem sido abordados pelas duas etapas anteriores. Nos recursos humanos da empresa, até agosto de 2012, estavam 309 empregados divididos em três grandes grupos funcionais, sendo 66 pesquisadores, 39 analistas e 204 assistentes. 0 quadro englobava 246 empregados do gênero masculino e 63 do gênero feminino. Os dados apurados descrevem e analisam as relações conceituais da oralidade e da prática do diálogo como estratégias de comunicação interna. A natureza quali-quantitativa desta pesquisa compreendeu um estudo exploratório, com base descritiva.

A estratégia quantitativa desenvolveu-se pelo uso de um instrumento amplo que foi construído com perguntas elaboradas com base no que disseram dirigentes e supervisores da empresa, nas primeiras fases da pesquisa. 0 questionário foi construído de modo a apreciar a percepção dos empregados sobre o discurso apresentado por seus líderes. Adotou-se, predominantemente, o uso de escala com intervalo de cinco pontos no questionário que estabeleceu um ponto de quebra bem definido entre concordância e discordância. Concordância e discordância (concordo totalmente e discordo totalmente) foram posicionadas em dois pontos extremos para tornar nítida a oposição e o distanciamento entre os estados de concordância e de discordância totais. A escala também continha dois pontos intermediários - um situado entre o ponto de quebra (não tenho certeza) e o polo da concordância (concordo) e outro intercalado pelo extremo da discordância (discordo). Os cinco pontos da escala intervalar ofereceram opções para que os entrevistados graduassem com maior conforto suas percepções a respeito dos temas internos da empresa, perguntados na pesquisa.

Responderam ao questionário 171 empregados. Na análise quantitativa, foram descartados doze respondentes pelo fato de não terem completado totalmente o questionário. Assim, para que o corpo de respostas fosse consistente ao longo de todas as questões, optou-se por considerar o conjunto de 159 respondentes que completaram integralmente 0 instrumento quantitativo dando forma a esta porção do corpus levantado. 0 estilo escolhido para apresentar analiticamente os resultados da etapa quantitativa foi a segmentação em blocos de análise, paralelo ao modelo de questões em escala de concordância e discordância. 


\section{ANÁLISE DA ETAPA QUANTITATIVA}

\section{Comunicação interna}

A pergunta referente ao direcionamento da divulgação das políticas, dos objetivos, das metas e dos resultados alcançados pela empresa para todos os empregados obteve $53 \%$ de respostas afirmativas. Os que responderam afirmativamente preencheram a questão seguinte, registrando quais meios eram utilizados para esse fim. A questão era uma pergunta aberta, de sorte que os respondentes tiveram espaço para mencionar quantos meios julgassem necessários e se expressar livremente. Para efeito de análise, as inferências dos sujeitos pesquisados foram agrupadas em classes de veículos distribuídos nas categorias de meios eletrônicos, internos, orais e administrativos. Note-se o destaque para meios orais, conforme revelam os dados agrupados no Quadro 1.

Quadro 1-Resumo dos modos de divulgação.

\begin{tabular}{|c|c|}
\hline MEIOS & RESULTADOS \\
\hline ELETRÔNICOS & 37 \\
\hline INTERNOS & 46 \\
\hline ORAIS & 53 \\
\hline ADMINISTRATIVOS & 06 \\
\hline
\end{tabular}

Fonte: Dados da pesquisa.

\section{Comunicação oral entre os empregados}

Foram 127 os empregados que confirmaram usar comunicação oral no processo de tomada de decisão com seus chefes diretos, representando $79 \%$ das respostas obtidas. Um grupo de $15 \%$ de entrevistados respondeu que usava, mas em algumas ocasiões e, $6 \%$ negaram o uso dessa classe de comunicação. Desses dados se pode depreender que os líderes eram reconhecidos pela sua oralidade e este era um método relevante desenvolvido pela comunicação interna da organização.

\section{Uso do diálogo}

Os empregados analisaram situações internas nas quais consideravam indispensável o diálogo ocorrer entre todos os níveis na empresa. As respostas solicitavam exemplos de situações em que a oralidade era imprescindível entre chefes de todos os níveis e empregados. Os respondentes citaram conjunturas cuja ênfase era no diálogo como estratégia de relacionamento e de gestão. Os dados analisados são os apresentados a seguir:

1) 0 diálogo criava expectativas, comprometimento e responsabilidade das partes envolvidas;

2) Era indispensável em situações que necessitavam de argumentação direta, discussão de ideias e negociação;

3) 0 diálogo em situações de conflito atua para não haver empregados insatisfeitos e chefes insatisfeitos;

4) Quando havia mudanças de normas ou regras internas, o diálogo era a estratégia mais acertada, mesmo que houvesse outras formas de divulgação;

5) Indispensável quando algum outro tipo de comunicação não surtiu efeito;

6) Situações que exigiam decisões em curto prazo;

7) Dialogar sempre que a comunicação não pudesse ser mal interpretada. 


\section{ANO 10 • NÚMERO 19 • 2º sem 2013 • ORGANICOM \\ DIÁLOGO E INTERAÇÕES FACE A FACE:

A análise reafirmou que a empresa destacava a oralidade na sua comunicação interna. Segundo o que revelaram os pesquisados sobre o uso do diálogo em todos os níveis da empresa, pode-se inferir que os gestores reconheciam o valor estratégico da oralidade para a comunicação interna.

A concepção dos gráficos a seguir aconteceu a partir da atribuição de um valor numérico: discordo totalmente - 1; discordo -2; não tenho certeza - 3; concordo - 4; concordo totalmente - 5. Dessa maneira, obteve-se a moda e a média para os blocos de questões. A moda representava a resposta cuja frequência era a maior. Tratou-se de um dado estatístico importante para avaliar qual era a resposta mais representativa de todo o conjunto. A média, diferentemente da moda, leva em consideração a variação ao longo de todo o corpo de respostas. Isso significa que a média é influenciada pela dispersão das respostas. Vale dizer que é possível que duas questões tenham a mesma moda (resposta com maior frequência), mas médias diferentes (a média sendo maior devido à presença relativamente de mais respostas positivas e a média sendo menor devido ao acúmulo de mais respostas negativas).

Foram construídos dois tipos de gráficos. 0 primeiro, de argolas, indica a relação entre a moda e a média, considerando apenas o conjunto de questões em cada bloco. 0 segundo, em estilo de radar, revela a tendência de discordância, concordância ou neutralidade a respeito de cada questão. A opção por esse tipo de gráfico se deu por representar visualmente, de maneira objetiva, a disposição das respostas, sendo que a tendência ao lado esquerdo indica concordância; ao lado direito, discordância, e a posição acima mostra a neutralidade do respondente.

Gráfico 1 - Relação entre a moda e a média encontradas para cada bloco de questões.

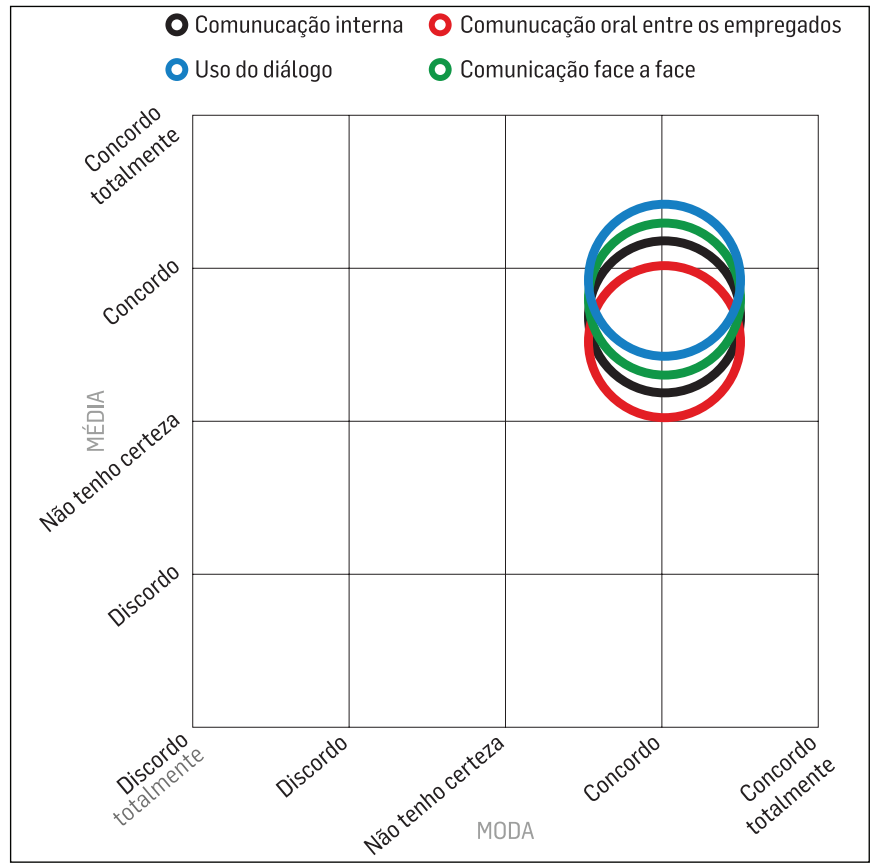

Fonte: Dados da pesquisa.

Observe-se que as argolas quase se confundem e estão concentradas em um único quadrante. Isso quer dizer que não há divergência marcante no modo em que os envolvidos percebem os quatro aspectos representados pelas cores empregadas no aro de cada argola. Cabe ressaltar que foram feitas análises segmentadas segundo o perfil dos respondentes para que houvesse a possibilidade de discutir eventuais divergências. 
A intersecção no centro, embora ovalada, é larga e aberta, o que representa uma significativa parcela da distribuição. Pode-se dizer que essa área, no centro da ilustração, refere-se a um grande número de respondentes. A quase disposição concêntrica dos anéis, ao mesmo tempo em que permite identificar a moda, também revela a dispersão, neste caso pequena, característica influenciadora da média. Tem-se então sólida evidência de que os tópicos representados são vistos de modo convergente.

0 que 0 Gráfico 1, na realidade, aponta é a relação obtida entre a moda e a média em cada bloco de questões. 0 tamanho de cada argola representa a frequência de respostas que a moda recebeu em cada bloco. Ou seja, quanto mais convergente a posição da argola, significa dizer que o bloco obteve relativamente mais respostas na moda. 0 gráfico também mostra que a concentração de respostas se deu exatamente no quadrante em que se reúnem as posturas de concordância.

Essa relação entre a moda e a média aqui encontrada expõe que os entrevistados admitem a força do uso da oralidade, do diálogo e das interações face a face no sistema de comunicação interna da empresa pesquisada. Um outro conjunto de gráficos, em formato de radar, foi elaborado para ilustrar, de modo particular, a análise em cada categoria por meio da seguinte segmentação: gêneros masculino e feminino; faixa etária de 21 a 30 anos, de 31 a 40 anos, de 41 a 50 anos, de 51 a 60 anos e mais de 60 anos; escolaridade com ensino fundamental completo, ensino médio completo e ensino superior completo.

\section{Comunicação interna}

O Gráfico 2 revela o comportamento predominantemente em concordância com as proposições do instrumento de pesquisa utilizado. Os números dispostos nos eixos referem-se à quantidade média de respostas dentro do bloco e indicam somatória das respostas em todo o bloco de questões voltadas ao eixo da comunicação interna consideradas na sua elaboração.

\section{Gráfico 2 - Composição com o agrupamento das respostas para comunicação interna.}

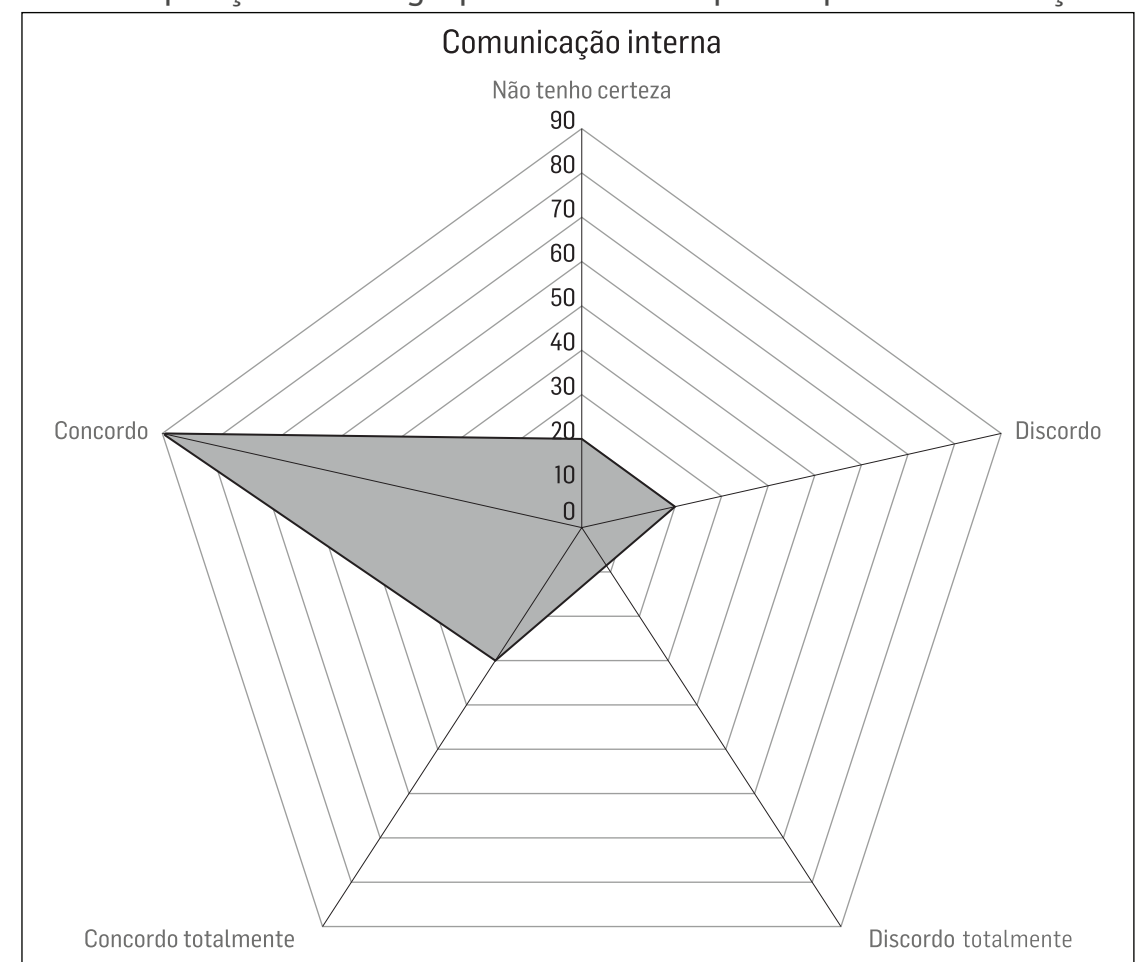

Fonte: Dados da pesquisa. 
Na região sombreada concentra-se a soma das respostas, podendo-se perceber uma forte inclinação para a esquerda - lado da postura de concordância. Há uma discreta penetração da figura para a direita, lado da discordância. 0 que se depreende da figura formada é a dominância da posição "concordo" e também uma acentuada inclinação para baixo, em direção à postura "concordo totalmente". A expressão da imagem constitui uma metáfora para o conceito de radar, sendo a escolha do formato para representar os dados dessa modalidade na pesquisa um modo de associação com a ideia de que se buscou captar o fenômeno na forma como faz um radar, como um "rastreamento". Revela informações obtidas de que os processos administrativos eram atividades com objetivos de apoio aos processos de comunicação interna para o cumprimento da missão da empresa que se concentrava em produção de conhecimento. Constatou-se que o conceito de comunicação interna era bem absorvido por parte significativa dos entrevistados, pois suas descrições mostraram-se conexas.

\section{Uso do diálogo}

O esquema estatístico apresentado no Gráfico 3 refere-se aos enunciados dos questionamentos postos aos empregados da estatal, conforme expõe o Quadro 2:

Quadro 2 - Relação de questões referentes ao bloco "uso do diálogo".

\begin{tabular}{|c|l|}
\hline Q1 & Meu superior imediato dá abertura para o diálogo com os empregados da equipe. \\
\hline Q2 & $\begin{array}{l}\text { Há situações em que o diálogo é a forma de comunicação indispensável entre chefes de todos os } \\
\text { níveis de autoridade e empregados. }\end{array}$ \\
\hline Q3 & Meu superior imediato ouve e acata o que seus subordinados relatam e sugerem para a sua área na empresa. \\
\hline Q4 & Eu tenho autonomia para propor ao meu superior imediato melhorias na execução de meu trabalho. \\
\hline
\end{tabular}

Fonte: Elaborado pela autora.

0 Gráfico 3 dá um ângulo de observação à distribuição dos dados que não representa unicamente somatória. Forma-se, agora, um conjunto único e acoplado de respostas pertencentes ao bloco "uso do diálogo". Obtém-se, portanto, uma visão de detalhe e uma visão de conjunto.

Gráfico 3 - Acoplamento das distribuições de respostas em uso do diálogo.

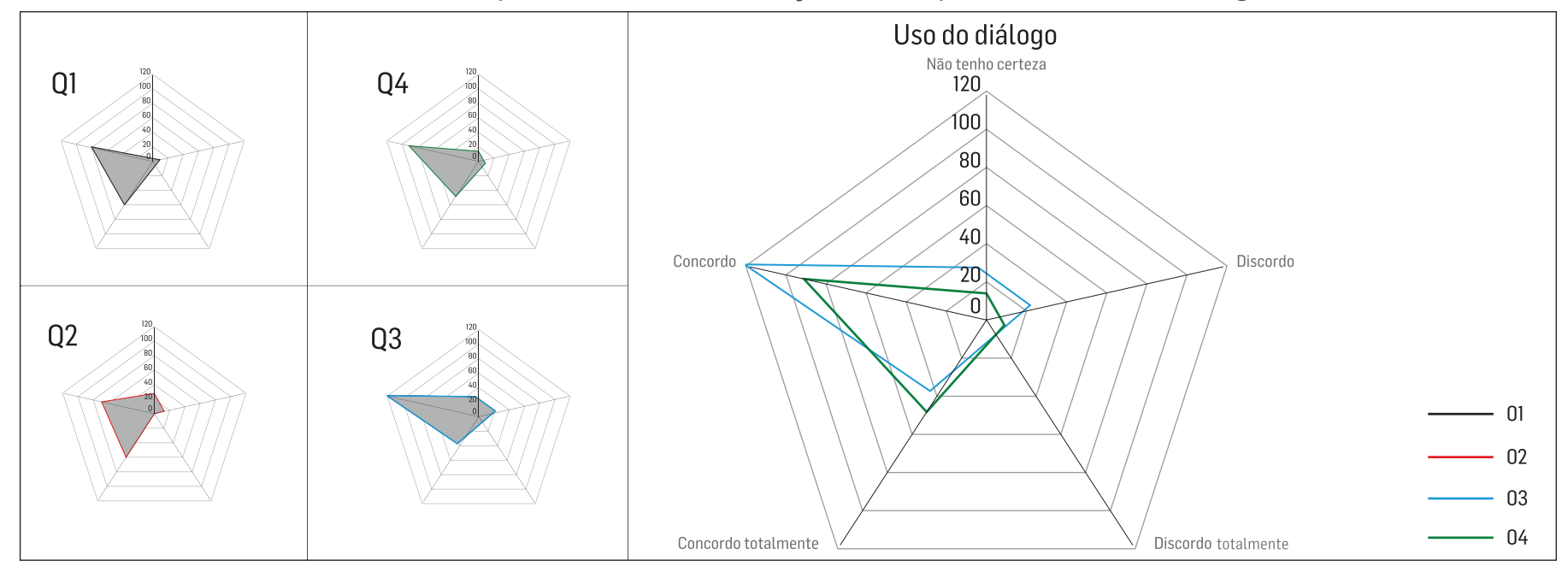

Fonte: Dados da pesquisa. 
Semelhança entre as imagens do lado esquerdo permite verificar, quando justapostas as quatro questões a que se referem, a proporção de respostas positivas para todas elas. Mais uma vez a incidência de respostas negativas apresentou indicativos baixos, comparadas às respostas positivas. De maneira especial, a primeira questão demonstrada (Q1) apresenta uma polarização significativa entre as respostas que indicam os eixos 4, "concordo", e 5, "concordo totalmente". Inclusive, importa ressaltar, nesse quadro esquemático, que a questão 1 foi a com maior indicativos de resposta no quinto eixo, de concordância completa, assinalada por 58 empregados respondentes.

Em continuidade, a segunda questão aqui descrita (Q2) apresenta a mesma polarização mostrada em Q1 (significativa entre as respostas que indicam os eixos quatro, "concordo", e eixo cinco, "concordo totalmente"), mas com menor incidência nas respostas, incidência que foi contraposta por um desvio significativo em direção ao eixo três, "neutro".

0 terceiro questionamento desse bloco de questões (Q3) apresenta uma nítida prevalência de respostas na direção do eixo quatro, "concordo", e uma significativa percepção de equivalência, como segunda escolha entre os entrevistados, entre os eixos dois, três e cinco, que se referem respectivamente às opções "discordo", "neutro" e "concordo totalmente".

Encerra o bloco de questões do Quadro 2 a questão 4 (Q4), convergindo a maioria de suas respostas no eixo quatro, "concordo", seguida de uma relevante indicação para o eixo cinco, "concordo totalmente", e um leve desvio para o eixo um "discordo totalmente". Afirmaram os entrevistados a presença do diálogo no dia a dia das relações líderes/liderados. Os meios de condução para os diálogos eram plataformas para conversar sobre fenômenos que, como tais, dialogavam entre si e interferiam no desempenho, na análise de cenários e de riscos, na imagem e nos relacionamentos da organização, entre outros.

\section{Comunicação face a face}

Os questionamentos apresentados aos sujeitos da pesquisa sobre o bloco "comunicação face a face" podem ser visualizadas no Quadro 3.

Quadro 3 - Relação de questões referentes ao bloco comunicação face a face.

\begin{tabular}{|c|l|}
\hline Q5 & Meu superior imediato discute face a face comigo ações para melhorar o meu desempenho \\
\hline Q6 & $\begin{array}{l}\text { Meu superior imediato encoraja os empregados a se expressarem face a face e fornece, com franqueza, } \\
\text { suas opiniões sobre o estilo dele de liderar. }\end{array}$ \\
\hline Q7 & $\begin{array}{l}\text { Que importância você atribui ao uso da comunicação oral (fala), do diálogo e da comunicação face a face } \\
\text { entre chefes e equipes na empresa? }\end{array}$ \\
\hline
\end{tabular}

Fonte: Elaborado pela autora.

Ao observar as representações isoladas das questões do bloco "comunicação face a face", percebe-se mais uma vez a tendência e o comportamento orgânico das afirmações feitas pelos entrevistados. 0 reforço às respostas positivas foi preservado e prevaleceu sobre as baixas indicações ocorridas de repostas negativas, conforme Gráfico 4. 


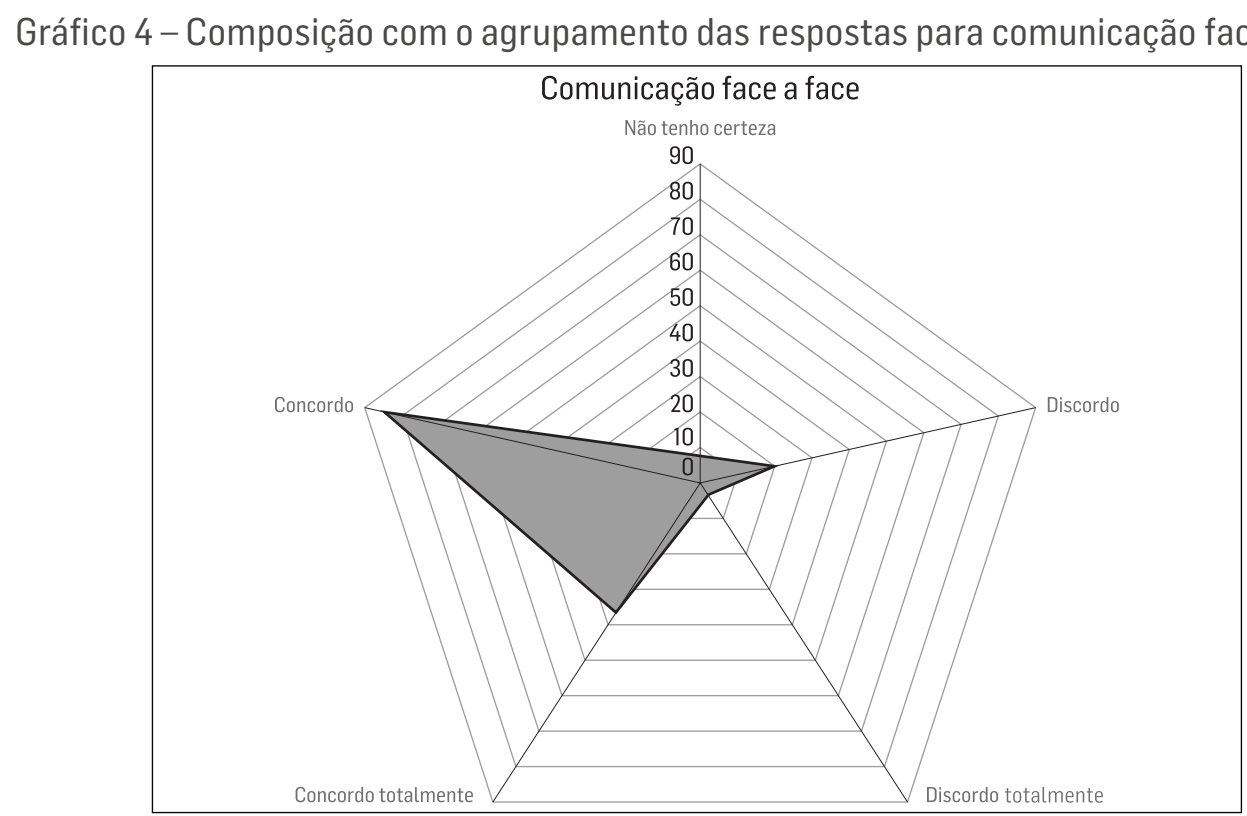

Fonte: Dados da pesquisa.

Ao observar a representação das questões do bloco "comunicação face a face", percebe-se mais uma vez a tendência e o comportamento orgânico das afirmações feitas pelos entrevistados. 0 reforço às respostas positivas foi preservado e prevaleceu sobre as baixas indicações ocorridas de repostas negativas. Ficou registrada a motivação para ouvir e a disposição para incentivar interações no ambiente interno da empresa. A conversa face a face mostrou-se muito utilizada pelos superiores para analisar rotinas, emergências, para orientar a tomada de decisão e suas equipes a respeito de questões estratégicas para a empresa. 0 Gráfico 5 (G5) detalha isoladamente cada uma dessas manifestações reveladas pelos informantes durante a pesquisa.

Gráfico 5 - Acoplamento das distribuições de respostas em comunicação face a face.

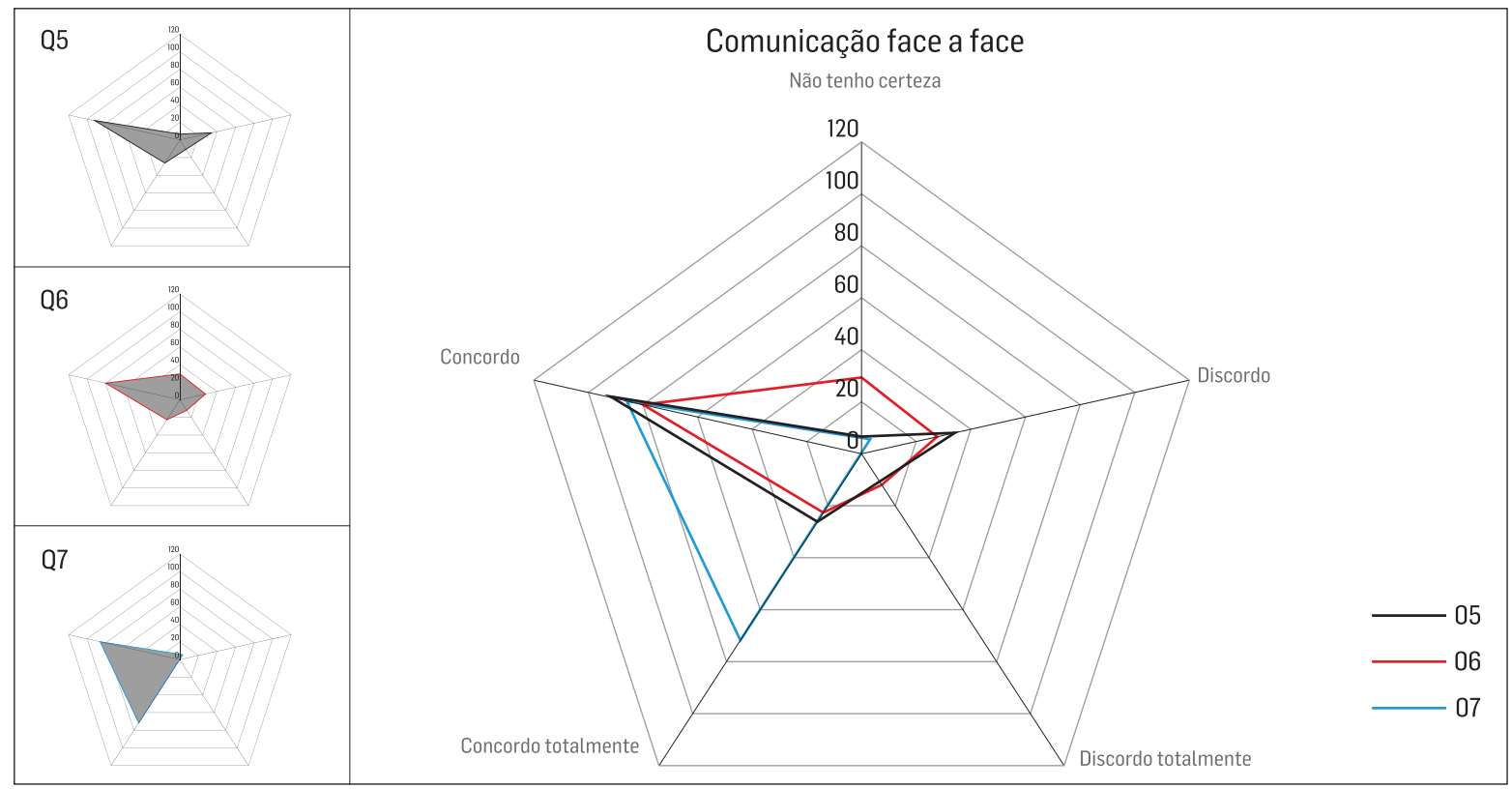

Fonte: Dados da pesquisa. 


\section{ANO 10 • NÚMERO $19 \cdot 2^{2}$ sem $2013 \cdot$ ORGANICOM DIÁLOGO E INTERACCÕES FACE A FACE: A FORÇA DA ORALIDADE NA COMUNICAÇÃO INTERNA}

A mesma característica de inclinação se mantém, reforçando que os envolvidos concordam e admitem que, em seu trabalho, a comunicação face a face é fundamental. De modo particular, a primeira questão (Q5) apresenta uma intensa incidência de respostas no eixo 4, "concordo", com um leve desvio para o eixo número cinco, "concordo totalmente", e, inclusive, uma significativa quantidade de resposta no eixo dois, "discordo", o que deforma o esquema visual em direção ao lado direito do gráfico.

A segunda questão demonstrada (Q6) apresenta a mesma incidência prioritária de respostas no eixo quatro, "concordo", com uma diferença da questão antecessora. Ela apresenta, se a leitura visual tiver como referência o centro do gráfico, um abaulamento significativo, demonstrando que todos os outros eixos receberam, aproximadamente, a mesma quantidade de respostas nos questionários válidos.

A terceira e última questão deste bloco (Q7) apresenta uma nítida polarização, com prevalência de respostas na direção do eixo quatro, "concordo", e significativa percepção de equivalência, como segunda escolha entre os entrevistados, para o eixo cinco, "concordo totalmente". Interessante ainda notar a mínima deformação gráfica sofrida em outros eixos, o que revela a quase unanimidade positiva dessa questão. Os empregados da estatal reconheceram a força da palavra falada como um meio híbrido que combina um conjunto de possibilidades para a delegação compartilhada de responsabilidades. A comunicação oral pode significar destacada vantagem na gestão organizacional, pois as pessoas têm necessidade de contato, de proximidade com seus pares, e este episódio pode ser viabilizado pelas interações orais e face a face.

\section{CONSIDERAÇÕES FINAIS}

A análise quantitativa alcançou argumentos que forneceram evidências de que, no ambiente pesquisado, a oralidade constrói a comunicação face a face, reconhecida como habilidade que projeta a competência do líder para conduzir equipes e atingir objetivos de comunicação interna.

A pesquisa trouxe subsídios para identificar características da oralidade que foram descritas nesse universo e que podem ser absorvidas pela comunicação interna, pois a empresa defendia a livre circulação de ideias, a participação dos empregados e atribuiu valor a esse fazer destinado à sua comunicação interna. Outras características pontuais da oralidade inferidas eram o foco nas pessoas e não em processos administrativos ou operacionais; a oralidade impactava a melhoria dos processos pela intervenção de pessoas; era também dinâmica e previa comportamento compatível com uma estratégia de gestão. Esse fenômeno imerso na organização foi naturalmente apontado e manifestado pelos sujeitos pesquisados.

O escopo da pesquisa foi averiguar como a oralidade produzia impactos para resgatar e fortalecer o diálogo entre dirigentes, gestores e equipes de empregados e se este seria o modo para sua precipitação ao campo das estratégias da comunicação interna. 0 locus podia ser conceitualmente definido como empresa humanizada, pois acomodava a comunicação como 0 lugar "da fala, da interação e do conhecimento, levando as pessoas ao desenvolvimento humano e de suas competências profissionais", conforme Marlene Marchiori, (2010, p. 139), e se revelou na análise de dados apresentada. Os dados foram capazes de apontar que a oralidade estava fortemente articulada ao estilo como a gestão era praticada na empresa estatal estudada. 0 nível de informação interna que os empregados declararam ter permitiu apreciar o desempenho do líder para disseminar informações para sua equipe e o reconhecimento coletivo de seu esforço. Os dados obtidos por meio das respostas às questões sobre comunicação interna sugeriram que a empresa reconhecia a oralidade como um componente a ser destacado na sua comunicação interna. Os empregados destacaram a relevância dos meios orais de comunicação, em clara referência ao diálogo como resultado de processo comunicacional. Eles manifestaram que esse era um reconhecimento presente no sistema de comunicação interna. 


\section{ANO 10 • NÚMERO $19 \cdot 2^{2}$ sem $2013 \cdot$ ORGANICOM \\ DIÁLOGO E INTERAÇÕES FACE A FACE:

Incorreções e equívocos de transmissão e de interpretação podem ocorrer com o uso de meios orais de comunicação, como aconteceria em qualquer modalidade de interação humana - isso não deve ser nunca afastado. No entanto, uma característica singular da oralidade - e aí reside uma significativa parcela de sua força - é a oportunidade que ela concede para observar o interlocutor e identificar o contorno da interpretação produzida e se esta representa um desvio ao que originalmente precisa ser comunicado.

A empresa estudada mostrou predisposição para admitir que a comunicação oral de fato influencia e atua no sentido de movimentar os sistemas de comunicação interna. Outras mídias internas cumpriam a função de disseminar informações de interesse coletivo. Contudo, percebeu-se que a empresa era um ambiente no qual as pessoas se mostraram maduras para apreciar e assumir posição diante de temas delicados ou sensíveis e que a comunicação oral, o diálogo e as interações face a face eram rotineiramente acessados pelos líderes na gestão de suas equipes. 0 assunto é rico o bastante para continuar a ser estudado.

\section{REFERÊNCIAS}

ARGENTI, Paul A. Comunicação empresarial: a construção da identidade, imagem e reputação. Rio de Janeiro: Elsevier, 2006.

BAKHTIN, Mikhail Mikhailovich. A interação verbal. In: BAKHTIN, Mikhail. Marxismo e filosofia da linguagem: problemas do método sociológico na ciência da linguagem. 3. ed. São Paulo: Hucitec, 1986. p. 110-127.

BOHM, David. Diálogo: comunicação e redes de convivência. São Paulo: Palas Athena, 2005.

FAIRHURST, Gail T.; PUTNAM, Linda. As organizações como construções discursivas. In: MARCHIORI, Marlene Regina (Org.). Comunicação e organização: reflexões, processos e práticas. São Caetano do Sul, SP: Difusão, 2010. p. 103-148.

GOFFMAN, Erving. Ritual de interação: ensaios sobre o comportamento face a face. Petrópolis, RJ: Vozes, 2011.

HALLIDAY, Tereza Lúcia. Discurso organizacional: uma abordagem retórica. In: KUNSCH, Margarida M. Krohling (Org.). Comunicação organizacional. Vol. 2. Linguagem, gestão e perspectivas. São Paulo: Saraiva, 2009. p. 31-52.

KUNSCH, Margarida Maria Krohling. Planejamento de relações públicas na comunicação integrada. 4. ed. - rev. e ampl. São Paulo: Summus, 2003.

LARKIN, Thomaz J. Face a face, a melhor forma de comunicar. Comunicação empresarial: a insubstituível oralidade, São Paulo, n. 57, p. 4-7, out.-dez. 2005. Entrevista concedida a Nara Damante.

MARCHIORI, Marlene Regina (Org.). Comunicação e organização: reflexões, processos e práticas. São Caetano do Sul, SP: Difusão, 2010. 